\title{
EFFECTS OF CAROXAZONE, A REVERSIBLE MONOAMINE OXIDASE INHIBITOR, ON THE PRESSOR RESPONSE TO INTRAVENOUS TYRAMINE IN MAN
}

\author{
A. MARTINI, L. BONOLLO \& F.B. NICOLIS \\ Medical Department, Farmitalia-Carlo Erba, \\ Milan, Italy \\ R. SEGA, A. PALERMO \& E. BRAIBANTI \\ Institute of Patologia Medica V, L. Sacco Hospital, \\ University of Milan, Milan, Italy
}

1 Caroxazone is a new antidepressant drug with reversible MAO-inhibitory activity.

2 The pressor effect of intravenously injected tyramine has been evaluated in six male healthy volunteers before, during oral treatment with caroxazone $200 \mathrm{mg}$ three times daily and at different time intervals after discontinuation of treatment.

3 Caroxazone produces a moderate tyramine supersensitivity.

4 The reversibility of MAO-inhibition produced by caroxazone is clearly reflected by the time-course of tyramine supersensitivity. In fact, tyramine potentiation does not accumulate with caroxazone cumulative dose, while it is correlated to drug plasma levels and disappears rapidly (half-life 1.5 days) upon discontinuation of treatment.

5 Caroxazone seems to be safer and more manageable than all other clinically available MAOinhibitors which produce irreversible inactivation of MAO.

\section{Introduction}

Caroxazone, 2-oxo-2H-1,3-benzoxazine-3(4H)acetamide, is a new psychotropic agent which in clinical studies was shown to possess a relevant antidepressant activity (Cecchini et al., 1978; Conti et al., 1980). Recent biochemical studies (Moretti et al., 1978; Moretti et al., in preparation) characterized caroxazone as a reversible MAO-inhibitor. These two properties - antidepressant activity and reversible MAO-inhibitory activity - may be related even if they need not necessarily be. The reversibility of the action of caroxazone is a property not shared by any other MAO-inhibitor presently available for the management of depressive illness (Byck, 1975).

Due to the clinical relevance of the interaction between MAO-inhibitors and indirectly acting sympathomimetic amines, a study was carried out in healthy volunteers in order to evaluate the possible interaction between caroxazone and tyramine administered by i.v. route. In fact, while the potentiation of tyramine produced by irreversible MAOinhibitors in man was well investigated, there are no data at our knowledge concerning reversible inhibitors.

\section{Methods}

The study was carried out in six healthy male volunteers aged between 23 and 26 years. The study subjects had not taken any drug for 10 days prior to the beginning of the trial. Administration of drugs during the study, as well as during the 2 week period following the end of the study, was not permitted. The subjects were also required to adhere to specific restrictions regarding food consumption during treatment with MAO-inhibitors; in particular, foods with high tyramine content and alcoholic beverages were excluded. The effect of intravenously injected tyramine on blood pressure was evaluated in each subject before caroxazone administration and on day 1 and day 7 during oral administration of caroxazone at a dose of $200 \mathrm{mg}$ three times daily.

The challenges performed during treatment were done at $2 \mathrm{~h}$ intervals after the morning dose of caroxazone.

In order to determine the duration of the effect of caroxazone after discontinuation of treatment, subjects were selected for reevaluation in the following manner: two subjects after 1 day, two after 3 days, one after 5 days and one after 7 days. 
Tyramine $\mathrm{HCl}$ (Fluka, Switzerland) was dissolved in saline containing $0.05 \%$ sodium metabisulphite in concentrations of 0.5 and $2 \mathrm{mg} / \mathrm{ml}$ (as base). The solutions were sterilized by filtration and sealed under nitrogen in dark glass vials, each containing $4 \mathrm{ml}$.

The tyramine challenge was done with the patient resting supine. An intravenous infusion of isotonic saline was started in one arm and indirect blood pressures were determined in the other arm using a mercury manometer and inflatable cuff.

The blood pressure was measured every 2 min until stabilized. Then, single injections of placebo (isotonic sodium chloride solution) or tyramine in increasing doses starting with $0.25 \mathrm{mg}$ per subject were given through a three-way stop-cock at the proximal end of the infusing tubing.

After each injection the catheter was immediately flushed with $3 \mathrm{ml}$ of saline. The blood pressure was recorded every minute until the systolic pressure returned to baseline, then another injection was given. The tyramine dose was increased until a rise in systolic blood pressure of at least $30 \mathrm{mmHg}$ was reached. Once this was achieved, varying doses of tyramine ranging from the minimally effective to the highest injected dose were given in random order in order to have, for each subject, a duplicate response at three dose levels at least. Log dose-response regression lines were calculated by standard least square technique both for the peak systolic pressor response and for the area under the pressor responsetime curve (AUC) determined by trapezoidal integration.

The procedure was double-blind because neither the pressure recorder nor the subject were aware of the tyramine dose on each occasion injected and moreover physiological solution (placebo) injections were randomly interposed to those of tyramine.

The possible influence of sources of variation unrelated to drug factors on the outcome of the study was also evaluated. In three subjects, selected at random from the study group, new dose-response curves for the pressor effect of tyramine were obtained 15-20 days after the first study, both in baseline conditions and after one day of placebo administered under double-blind conditions.

The placebo was supplied in tablets indistinguishable from those of caroxazone and containing a bitter extract to simulate its taste.

The trial was carried out in the same manner as described above.

As a precaution, phentolamine $(10 \mathrm{mg} / \mathrm{ml})$, procainamide $(100 \mathrm{mg} / \mathrm{ml})$ and propranolol $(1 \mathrm{mg} / \mathrm{ml})$ were always at hand.

An ECG was recorded continuously during the study.

\section{Results}

The results obtained in the placebo treated subjects are summarized in Figure 1. The pressor responses before and after placebo administration were compared by the Hotelling multivariate $T^{2}$ test on ' $a$ ' (point of interception between the regression line and the axis of the ordinate) and 'b' (slope of the regression line).

For both peak and AUC pressor responses the mean values for each dose of tyramine are very close to each other, thus providing evidence against the hypotheses of either a 'placebo effect' or a residual effect of the first test which could systematically influence the second test performed with an interval of 1 day only.

The results obtained in caroxazone treated subjects on basal conditions and after 1 and 7 days of treatment are reported in Figure 2. The Hotelling $T^{2}$ test on the regression parameters ('a' and 'b') showed significant differences between day 1 or 7 and baseline for both the peak and the AUC of the pressor response. Therefore, a two-way analysis of variance (time and subjects) was performed separately on the ' $a$ ' and ' $b$ ' values. The four analyses of variance showed that caroxazone treatment results in a significant increase of both ' $a$ ' and ' $b$ ' values after 1 and 7 days of treatment with respect to baseline; the ' $b$ ' values are not significantly different either for peak or for AUC pressor responses on day 1 and 7 , while the differences are significant for the ' $a$ ' values.

Since, due to the lack of parallelism, it was impossible to evaluate quantitatively the potentiation of the pressor effect of tyramine by caroxazone using the parallel line bioassay, linear interpolation was used to determine the doses of tyramine which produced a $30 \mathrm{mmHg}$ pressure rise (ED $30 \mathrm{mmHg}$ ) or a $60 \mathrm{mmHg} \times \min$ AUC (ED $60 \mathrm{mmHg} \times \mathrm{min})$ and the evaluation was carried out on these EDs (Table 1).

A two-way analysis of variance was performed on the logs of baseline values and values after 1 and 7 days of caroxazone treatment. Caroxazone significantly reduced the equipotent doses of tyramine for the peak and AUC of the pressor response both after 1 and 7 days of treatment, while the difference between day 1 and 7 was close to significance $(0.05<$ $P<0.10$ ) only for AUC.

In order to evaluate the post-treatment period on which, given the limited number of observations at various times, the analysis of variance could not be performed, we calculated the 'tyramine sensitivity' i.e. the ratio of the EDs in baseline conditions and in the various treatment situations.

Since on day 5 and 7 after treatment discontinuation only one subject was challenged, the calculation 

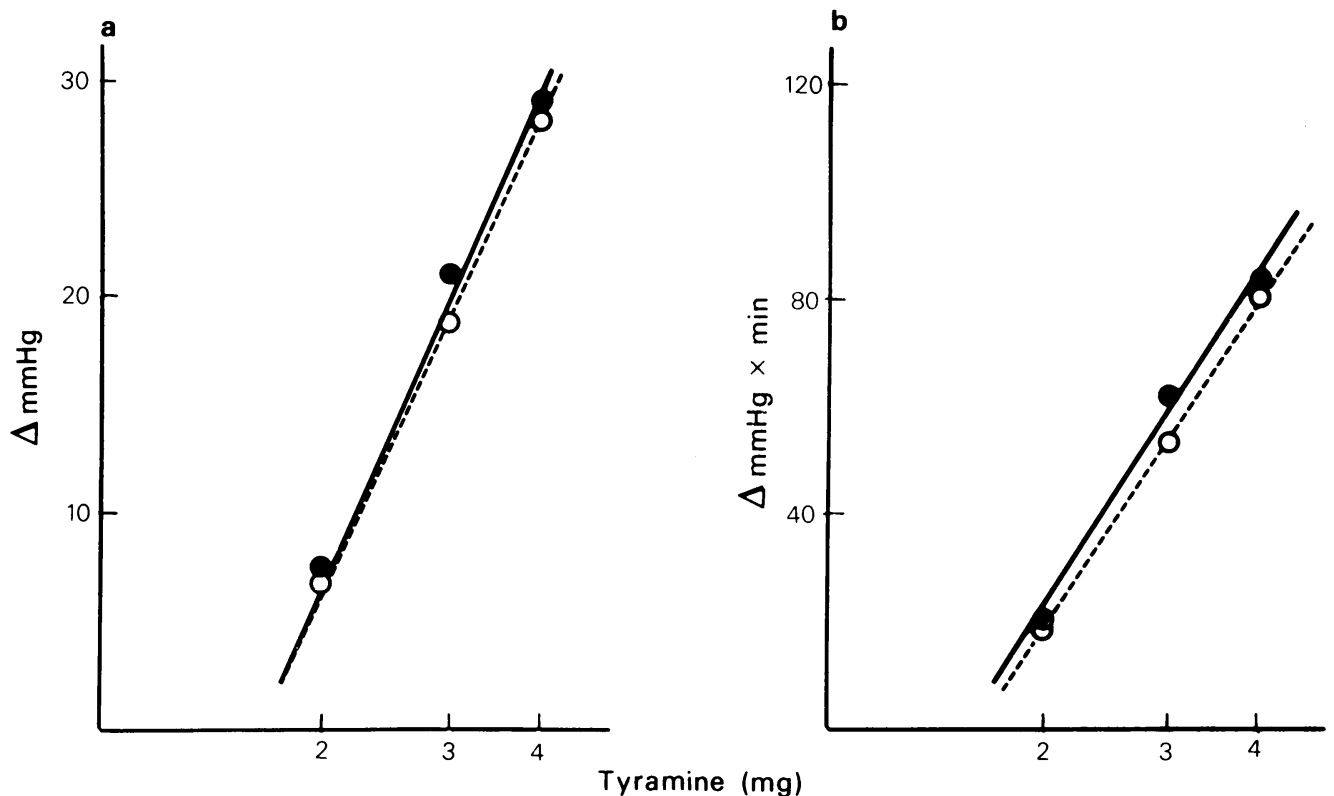

Figure 1 Log dose-response curves of peak (a) and AUC (b) increases in systolic pressure induced by i.v. tyramine in three subjects before $(\bullet)$ and after $(O) 1$ day of oral treatment with placebo.

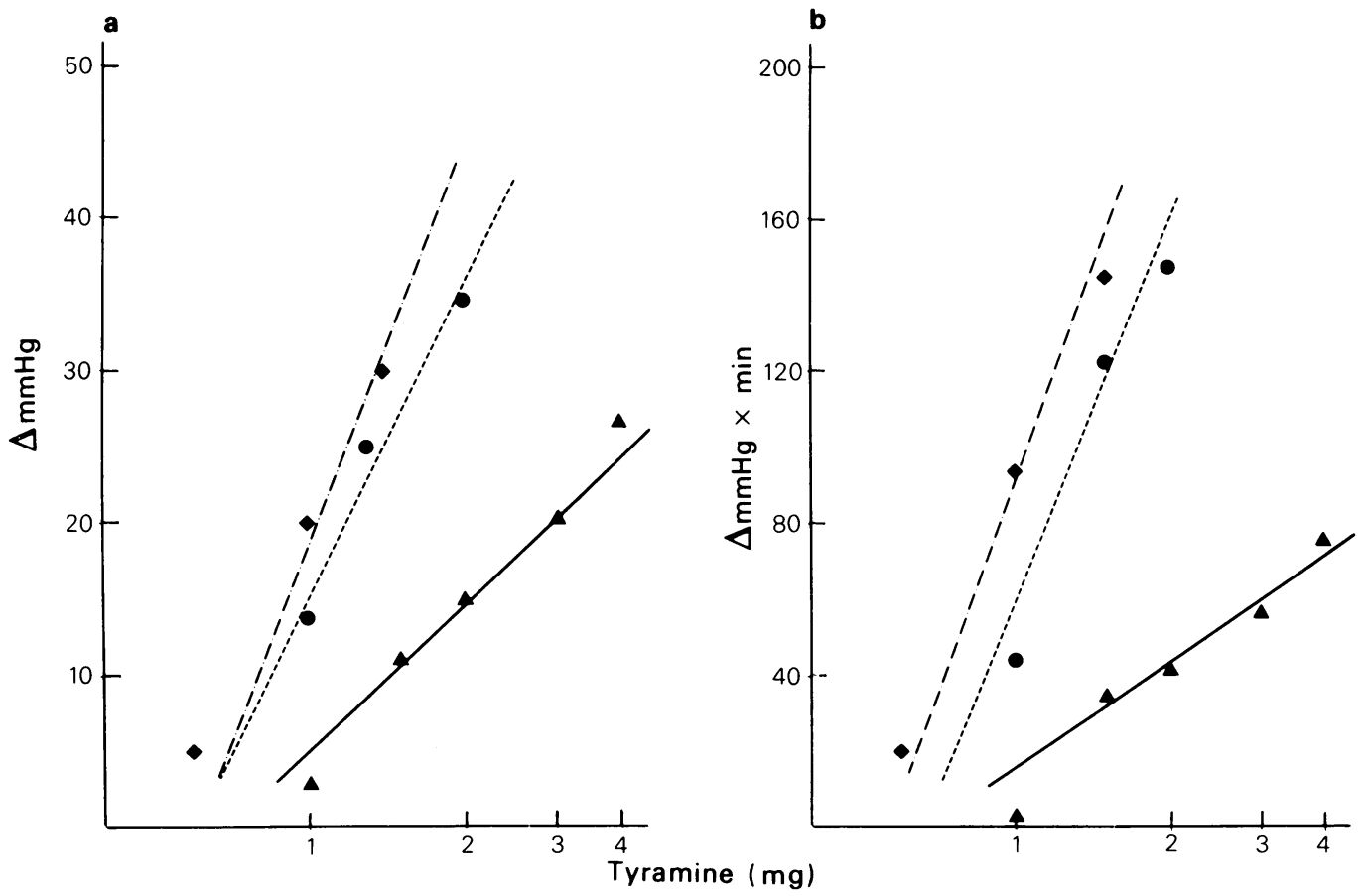

Figure 2 Log dose-response curves of peak (a) and AUC (b) increases in systolic pressure induced by i.v. tyramine in 6 subjects before $(\Delta)$ and after $1(\bullet)$ and $7(\bullet)$ days of oral treatment with caroxazone. 
Table 1 ED $30 \mathrm{mmHg}$ and ED $60 \mathrm{mmHg} \times$ min for i.v. tyramine in six subjects before, during (day 1 and 7 ) and on different days after the end of oral treatment with caroxazone $200 \mathrm{mg}$ three times daily.

\begin{tabular}{|c|c|c|c|c|c|c|c|c|c|c|c|c|c|c|}
\hline \multirow{4}{*}{ Subjects } & \multicolumn{14}{|c|}{ Tyramine (mg) } \\
\hline & \multirow{3}{*}{$\begin{array}{l}\text { Pre- } \\
\text { treat }\end{array}$} & \multicolumn{6}{|c|}{$E D 3 C \mathrm{mmHg}$} & \multicolumn{7}{|c|}{$E D 60 \mathrm{mmHg} \times \min$} \\
\hline & & \multicolumn{2}{|c|}{ Caroxazone } & \multicolumn{4}{|c|}{ Days after treatment } & \multirow{2}{*}{$\begin{array}{l}\text { Pre- } \\
\text { treat }\end{array}$} & \multicolumn{2}{|c|}{ Caroxazone } & \multicolumn{4}{|c|}{ Days after treatment } \\
\hline & & day 1 & day 7 & 1 & 3 & 5 & 7 & & day 1 & day 7 & 1 & 3 & 5 & 7 \\
\hline 1 & 4.36 & 2.09 & 1.32 & 1.70 & & & & 3.80 & 1.42 & 0.80 & 0.99 & & & \\
\hline 2 & 48.98 & 2.45 & 2.09 & 3.39 & & & & 10.00 & 1.06 & 0.98 & 1.72 & & & \\
\hline 3 & 3.72 & 1.66 & 1.24 & & 4.57 & & & 2.33 & 0.98 & 0.80 & & 2.60 & & \\
\hline 4 & 4.90 & 2.14 & 1.38 & & 3.98 & & & 2.87 & 1.16 & 0.33 & & 2.11 & & \\
\hline 5 & 2.14 & 0.98 & 0.98 & & & 4.99 & & 1.32 & 0.65 & 0.67 & & & 1.33 & \\
\hline 6 & 4.17 & 1.74 & 1.82 & & & & 4.96 & 3.13 & 0.99 & 0.76 & & & & 2.52 \\
\hline $\begin{array}{l}\text { Geometric mean } \\
\text { Confidence limits }\end{array}$ & 5.74 & 1.78 & 1.42 & & & & & 3.17 & 0.95 & 0.67 & & & & \\
\hline$(P=0.95): \begin{array}{l}\text { lower } \\
\text { upper }\end{array}$ & $\begin{array}{r}1.81 \\
18.20\end{array}$ & $\begin{array}{l}1.26 \\
2.53\end{array}$ & $\begin{array}{l}1.06 \\
1.90\end{array}$ & & & & & $\begin{array}{l}1.58 \\
6.36\end{array}$ & $\begin{array}{l}0.63 \\
1.43\end{array}$ & $\begin{array}{l}0.51 \\
0.88\end{array}$ & & & & \\
\hline $\begin{array}{l}\text { Significance of } \\
\text { differences }(P) \text { : } \\
\text { day } 1 v \text { pre-treatment } \\
\text { day } 7 v \text { pre-treatment } \\
\text { day } 1 v \text { day } 7\end{array}$ & & $\begin{array}{c}<0.01 \\
<0.01 \\
\quad \text { NS }\end{array}$ & & & & & & & $\begin{array}{l}<0.01 \\
<0.01 \\
<0.10\end{array}$ & & & & & \\
\hline
\end{tabular}

of the confidence limits of these activity ratios was carried out by means of the error proportion theory. This estimation was performed assessing homogeneous variances in comparison with that observed at baseline.

Performing this calculation permitted us to compare our results with those obtained by other investigators using different MAO-inhibitors.

The tyramine sensitivity values obtained from peak and AUC pressor response are reported with the relative confidence limits in Figure 3 . The two curves show a similar time-course; the potentiation of tyramine is significant on both day 1 and 7 of treatment since the confidence limits $(P=0.95)$ do not include the baseline value. The difference between day 1 and 7 was not significant as evidenced by the extensive overlapping of confidence limits.

Following discontinuation of caroxazone treatment, tyramine sensitivity is rapidly decreased and returns to baseline within 3 days. The approximate half-life is of about 1.5 days for both curves.

All subjects reported palpitations and precordial distress in response to the larger doses of tyramine. These transient symptoms disappeared within $5 \mathrm{~min}$. The potentiation of tyramine by caroxazone was evident also in this connection: during treatment with caroxazone the doses at which patients complained of side-effects were generally smaller than under basal conditions.

\section{Discussion}

The results of our trial show that the reversibility of the MAO-inhibition produced by caroxazone can also be evidenced by the i.v. tyramine interaction model in humans treated with a dosage schedule already shown to be therapeutically effective (Cecchini et al., 1978; Conti et al., 1980). In fact, after discontinuation of treatment with irreversible MAOinhibitors the pressor response to tyramine returns to normal slowly with a half-life of approximately 14 days (Palm et al., 1971; Pettinger, Soyangco \& Oates, 1968) which is correlated to 'de novo' synthesis of the inhibited enzyme(-es).

On the contrary, after discontinuation of caroxazone, the recovery of normal reactivity to tyramine is rapid. The duration of caroxazone induced effects is about ten times less with respect to that of irreversible inhibitors. The recovery half-time is incompatible with MAO re-synthesis, while it is clearly related to caroxazone plasma half-life in man which is of about $20 \mathrm{~h}$ (Moretti et al., 1981).

Moreover the effects of irreversible MAOinhibitors are cumulative in time and independent of the drug levels in plasma. In fact, Palm et al. (1971) and Pettinger et al. (1968) report that the continuation of treatment with benmoxine, furazolidone and pargyline results in a progressive increase in tyramine sensitivity in relation to the cumulated dose. 


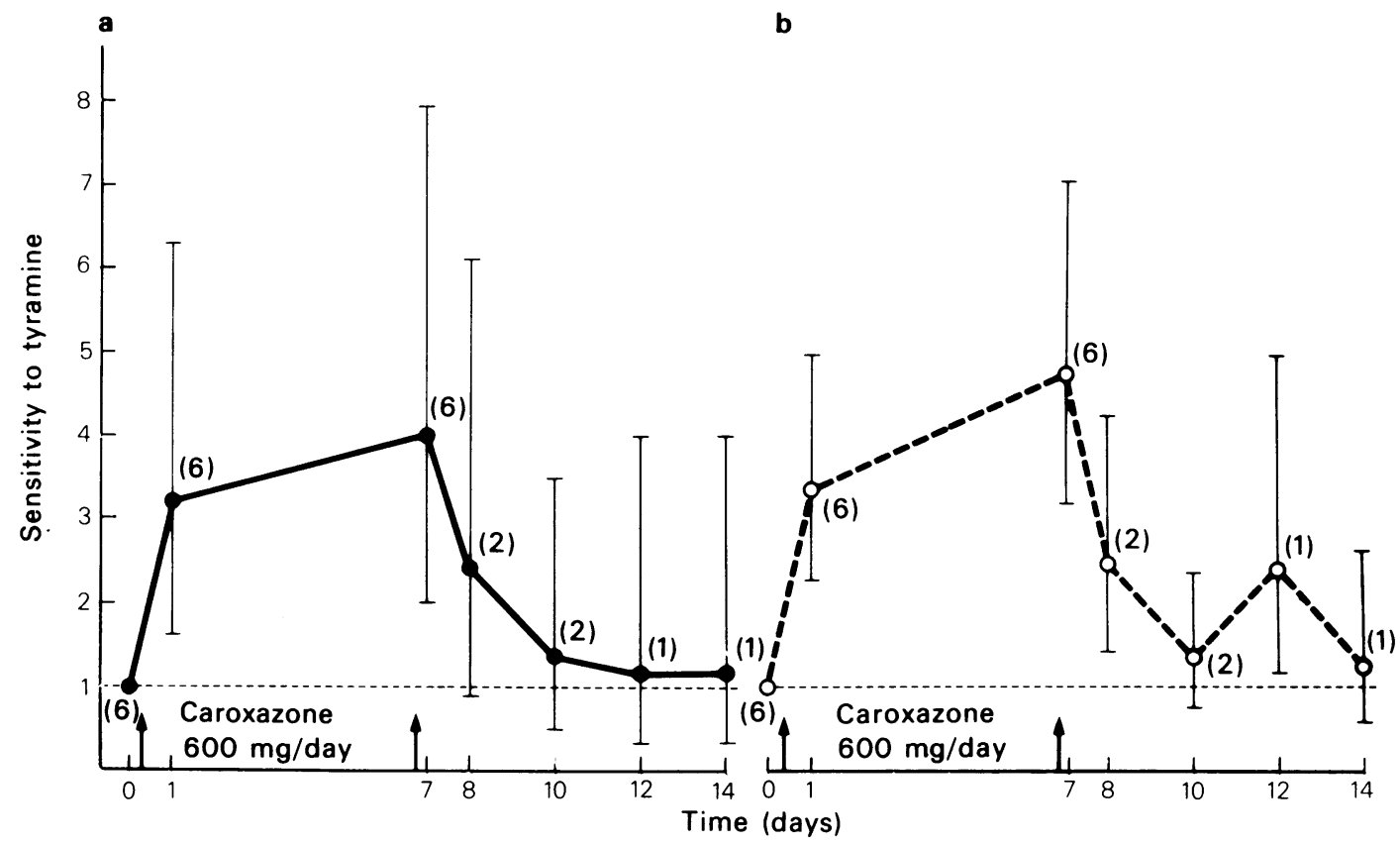

Figure 3 Time-course of sensitivity to tyramine in subjects receiving caroxazone. In ordinate the ratio of the control to treatment or post-treatment dose of tyramine required to increase systolic blood pressure by $30 \mathrm{~mm} \mathrm{Hg}(\mathrm{a}) \mathrm{or}$ $60 \mathrm{mmHg} \times \min (\mathrm{b})$. Bars represent confidence limits for $P=0.95$. In brackets the number of subjects tested at each time point.

On the contrary, for an inhibitor which acts reversibly, a correlation should exist between MAOinhibition and plasma concentration: the potentiation of i.v. tyramine should not increase once pharmacokinetic steady state has been attained. These theoretical expectations are in good agreement with the results obtained with caroxazone.

The increase in sensitivity to tyramine found between the first and the seventh day of caroxazone treatment is justified by the attainment of steady state plasma level during this time interval.

Since the enzyme inhibition by caroxazone is not cumulative, as a function of total dose, it is unlikely that the continuation of caroxazone treatment beyond the seventh day may cause further potentiation of the tyramine pressor effect.

Therefore the tyramine potentiation produced by caroxazone does not appear to reach the high values observed with irreversible MAO-inhibitors which upon repeated administrations induce an increase in tyramine sensitivity up to $10-20$ fold (Pettinger et al., 1968).

In conclusion, the reversibility of MAO-inhibition produced by caroxazone is clearly reflected by the time-course of the potentiation of the pressor effect of i.v. tyramine in man. The effect of caroxazone is correlated to its pharmacokinetics and is independent of the cumulative dose over time; after treatment discontinuation, tyramine sensitivity returns to basal values within 3 days.

The results obtained in this study may have therapeutic implications of some relevance. Firstly, caroxazone appears to be a safer drug than irreversible MAO-inhibitors since its effect on tyramine does not increase with chronic therapy up to levels which would be expected to carry a significant risk of hypertensive crisis (Pettinger et al., 1968). Secondly, after treatment discontinuation a normal diet (which does not exclude tyramine rich food) can be rapidly resumed while, on the contrary, after irreversible MAO-inhibitors a two-week interval is suggested before the resumption of a normal diet (Byck, 1975). Thirdly, the drug appears to be more manageable because the desired level of inhibition can be easily achieved by adjusting the dose in relation to the plasma levels.

The skilful technical assistance of Mr Pietro D'Orazio is gratefully acknowledged.

Statistical analyses were performed by the FarmitaliaCarlo Erba Unit of Biometry (Head: Dr V. Mandelli). 


\section{References}

BYCK, R. (1975). Drugs and the treatment of psychiatric disorders. In The pharmacological basis of therapeutics, eds Goodman, L.S. \& Gilman A., pp. 152-200.New York: MacMillan Publishing Co., Inc., Vth Edition.

CECCHINI, S., PETRI, P., ARDITO, R., BAREGGI, S.R. \& TORRITI, A. (1978). A comparative double-blind trial on the new antidepressant caroxazone and amitriptyline. J. int. med. Res., 6, 388-394.

CONTI, L., BONOLLO, L., MARTINI, A., FORNARO, P., GUERRINI, A., ROMERIO, C., SCILLIERI, E., SOVERINI, S., STRAMBA-BADIALE, M. \& CASSANO, G.B. (1980). Double-blind comparative study of the therapeutic activity and safety of caroxazone (F.I. 6654) and placebo in depressed inpatients. Curr. Ther. Res., 27, 458-473.

MORETTI, A., CACCIA, C., MARTINI, A., CALDERINI, G. \& AMICO, A. (1978). The mechanism of action of carox- azone. Communication at the Seventh International Congress of Pharmacology, Paris, July 16-21.

MORETTI, A., CACCIA, C., MARTINI, A., BONOLLO, L., AMICO, A., SEGA, R., NICOLELLA, V. \& NICOLIS, F.B. (1981). Effect of caroxazone, a new antidepressant drug, on monoamine oxidases in healthy volunteers. $B r$. J. clin. Pharmac., 11, 511-515.

PALM, D., FENGLER, H.J., GULLNER, H.G., PLANZ, G., QUIRING, K., MAY, B., HELMSTAEDT, D., LEMMER, B., MOON, H.K. \& HOLLER, Ch. (1971). Quantitation of irreversible inhibition of monoamine oxidase in man. Eur. J. clin. Pharmac., 3, 82-92.

PETTINGER, W.A., SOYANGCO, F.G. \& OATES, J.A. (1968). Inhibition of monoamino oxidase in man by furazolidone. Clin. Pharmac. Ther., 9, 442-447.

(Received July 11, 1980) 